\title{
De-escalation of biological therapy in inflammatory bowel disease: Benefits and risks
}

\author{
E Fredericks, ${ }^{1}$ FCP (SA), Cert Gastroenterology (SA), PhD; G Watermeyer, ${ }^{2}$ FCP (SA), Cert Gastroenterology (SA), MPH (SA) \\ ${ }^{1}$ Department of Biochemistry and Microbiology, Faculty of Science, Nelson Mandela University, Port Elizabeth, South Africa \\ ${ }^{2}$ Gastrointestinal Clinic, Department of Medicine, Faculty of Health Sciences, Groote Schuur Hospital and University of Cape Town, South Africa
}

Corresponding author: E Fredericks (esfred@eject.co.za)

The treatment of inflammatory bowel disease (IBD) is often challenging. It has a vexing and waning course with frequent relapses, despite adequate maintenance therapy. Biological agents have been available for the treatment of IBD for the last two decades, with impressive results. However, these drugs are costly and often have significant side-effects. Therefore, the benefit of aggressive treatment must be carefully balanced against the risk of serious adverse events. Despite good clinical outcomes, patients often request to discontinue the drugs because of cost and detrimental effects, especially the risk of malignancy. This review focuses on the benefits of biological treatment, strategies to de-escalate therapy, risk of relapse when these agents are discontinued and success with retreatment with the same or a similar biological agent.

S Afr Med J 2019;109(10):745-749. https://doi.org/10.7196/SAMJ.2019.v109i10.14074

Inflammatory bowel disease (IBD) is a chronic, relapsing and remitting inflammation of the intestine, posing significant treatment challenges. Maintenance treatment with an immunomodulator (IM) and/or aminosalicylates is often required to reduce disease relapse in Crohn's disease (CD) and ulcerative colitis (UC). Despite adequate maintenance therapy, some patients experience disease flares that require escalation to biological therapy..$^{[1,2]}$

As there is currently no cure available for IBD, the treatment strategy for patients focuses on induction and maintenance of remission. As South Africa (SA) is a developing country and biological drug cost prohibitive, the (accelerated) step-up treatment strategy is used, with high-dose corticosteroids the favourite induction agent. This is followed by maintenance therapy with aminosalicylates or an IM to maintain remission. Examples of IM agents include azathioprine, 6-mercaptopurine and methotrexate. Thioguanine (Lanvis) is also used for severe IBD in an off-label setting in some centres. Patients who experience disease flares while receiving adequate doses of maintenance therapy and/or require a second course of high-dose corticosteroid therapy within a short treatment interval (usually 1 year), are escalated to biological therapy. Other indications for biological treatment include steroid-dependant and steroid-refractory disease.

Since the launch of infliximab 20 years ago, the number of biological agents introduced to the market has grown exponentially, especially in the past decade. Currently available classes of biological agents for IBD in SA include: (i) tumour necrosis factor alpha (TNF alpha) antagonists, which include infliximab, adalimumab and golimumab; (ii) the integrin antagonist vedolizumab (Entyvio); and (iii) ustekinumab, a newly introduced interleukin (IL)-12 and IL-23 antagonist (Stelara). ${ }^{[3-7]}$ The last two agents are awaiting SA Health Products Regulatory Authority (SAHPRA) approval and currently only have limited availability on compassionate basis.

Biological agents have revolutionised the treatment of IBD, especially over the past decade. A recent systematic review by CoteDiagneault et al. ${ }^{[8]}$ comprehensively summarised the success rate of IBD treatment with biologics. A detailed discussion of this topic is beyond the scope of this article, but salient points are summarised below. Although study designs and patient characteristics differ in various studies, it is apparent that induction and maintenance of remission rates are $<50 \%$ for both CD and UC. Analysing the maintenance of remission data, it is clear that clinical response rates are better than clinical remission rates, which in turn are better than mucosal healing. Data from real-world registries have far superior clinical response and remission rates than clinical trial data. A recent systematic review concluded that biological therapy effectively reduced hospitalisation by half and surgery by $33-77 \% \cdot{ }^{[9]}$ More importantly, it reduced steroid-free remission by $30 \% \cdot{ }^{[10]}$

Secondary loss of response (LOR) while the patient is being treated with a biological agent is a significant problem in IBD management and often results in disease relapse. It is estimated that up to $30 \%$ of patients do not respond to induction therapy and a further $30 \%$ develop LOR. ${ }^{[11]}$ LOR is believed to be secondary to the development of drug antibodies, with resultant low drug trough levels. This is often remedied by dose escalation of the biologic in question if the trough drug level is low or by switching to a different agent if the drug level is within target range. For example, if a patient is maintained on a standard dose of infliximab ( $5 \mathrm{mg} / \mathrm{kg}$ every 8 weeks), it will increase to a $10 \mathrm{mg} / \mathrm{kg}$ dose every 8 weeks with dose escalation. However, more often, the dosing frequency is also reduced in addition to dose escalation, resulting in a $10 \mathrm{mg} / \mathrm{kg}$ dose given every 6 weeks or even every 4 weeks. Similar treatment strategies exist for the other agents.

\section{Biological therapy}

The clinical efficacy of biological therapy in moderate to severe CD and UC is well established in the scientific literature. ${ }^{[12]}$ The decision to initiate biological therapy in this setting is often made easily, as treatment objectives and algorithms are clear. ${ }^{[13]}$ The clinical benefits of biological therapy include: higher rates of mucosal healing, improved quality of life, reduced hospital admission rates and fewer surgical interventions. However, biological therapy is associated with significant adverse events and high treatment cost. The major negative factors are serious infections and possible increased risk of malignancy. ${ }^{[14]}$ 
Therefore, when deciding to start biological therapy in IBD, the risk of treatment should be carefully balanced against the benefit, i.e. the danger of uncontrolled or untreated IBD should always be greater than that of therapy. However, it is currently not clear when to de-escalate biological therapy. The rationale for de-escalation includes:

- Cost of therapy. Treatment cost for indefinite treatment with biological agents is considerable. ${ }^{[15]}$ The cost escalates notably if the patient requires a dose increase and/or reduced dosing frequency. The direct cost for the first year of biological therapy in SA for 2018 is set out in Table 1. The total cost excludes hospitalisation, consumables for infusion and endoscopy costs, which further increases overall cost significantly.

- Safety concerns. Anti-TNF antagonists especially have a significant adverse profile, adding to the morbidity with regard to IBD treatment. However, newer and safer classes of biological agents are currently awaiting SAHPRA approval, which should improve the safety profile. Although not evidence based, the possibility remains that some toxicity of biological treatment may be directly related to the cumulative duration or dose of the drug, a concern not always considered in clinical practice.

- Patient-specific reasons

- Adherence to drug therapy. This has often been a bone of contention between the patient and the treating physician. Up to $30 \%$ of IBD patients discontinue maintenance therapy, ${ }^{[16]}$ although compliance with biological therapy was high $-94 \%$ in a recent Italian study. ${ }^{[17]}$

- Safety concerns. Patients often want to de-escalate therapy, especially when they are clinically well. The same applies to pregnant and breastfeeding patients. Patients are not keen to take unnecessary risks and their decision to discontinue therapy is usually based on: $(i)$ their chances of disease relapse; and (ii) when they do relapse, how long it will take to reach clinical remission with the same or a similar drug.

In the next section, we try to answer some of these questions and implications.

\section{Risk of relapse after withdrawal of biological agents}

There is no randomised controlled study that has evaluated the effect of withdrawal of a biological agent as monotherapy in IBD. Available studies investigated infliximab and adalimumab in combination with IM therapy. No similar comparative studies are available for other biological agents. A recent meta-analysis considering relapse after withdrawal of anti-TNF therapy (infliximab and adalimumab) showed UC and CD relapse rates of 38\% and $44 \%$ after 6 months and $28 \%$ and $42 \%$ after 1 year, respectively. ${ }^{[18]}$ Inversely, $>60 \%$ of patients with $\mathrm{CD}$ and $\geq 70 \%$ of patients with UC remain in remission 1 year after withdrawal of anti-TNF therapy. In the STORI (infliximab diSconTinuation in crOh'ns disease patients in stable RemIssion) trial, discontinuing anti-TNF treatment in $\mathrm{CD}$ patients receiving combination therapy, the relapse rate was $43.9 \%$ after 12 months and $52.2 \%$ after 24 months, with a median of 16.4 months to relapse. ${ }^{[19]}$ In UC studies, where anti-TNF therapy was withdrawn and patients remained on an IM, stopping anti-TNF was associated with relapse rates of $14.0-41.8 \%$ after 12 months and $25.0-58.7 \%$ at 24 months. ${ }^{[2,21]}$ Relapse rates were significantly reduced when mucosal healing was used as the reference point to de-escalate anti-TNF therapy (17 - 24\% after 12 months and 25 - 35\% after 24 months). ${ }^{[22]}$

Limited data exist for longer follow-up after withdrawal of biological agents. There is a relapse risk of $50 \%$ after withdrawal at 24 months of anti-TNF therapy, according to 1 meta-analysis and 1 systematic review. ${ }^{[18,23]}$ Reported long-term cumulative relapse rates are between $49 \%$ and $88 \%$. A period of $5-10$ years off biological treatment is associated with relapse rates of $>70 \%{ }^{[24-26]}$ Therefore, the risk of disease relapse increases with time, necessitating the re-introduction of biological therapy. However, a minority of patients remain in remission indefinitely without requiring any active treatment.

\section{Risk factors for relapse after treatment withdrawal}

Various factors predicting relapse have been evaluated and are categorised as follows:

- Patient factors. The outstanding risk factor for disease relapse after de-escalation of anti-TNF therapy is continued smoking in CD patients. ${ }^{[27]}$ The reverse is true for smoking in UC, but should be discouraged in all patients, as the negative effects of smoking outweigh the potential benefit in UC. Young age at diagnosis appears to be associated with severe disease in both CD and UC, but data are conflicting. ${ }^{[28]}$ Gender per se is not a risk factor for aggressive IBD; however, young males are at increased risk of severe $\mathrm{CD}{ }^{[29,30]}$

- Disease factors. Mucosal healing at the time of treatment withdrawal is associated with a reduced risk of disease relapse. ${ }^{[18]}$ For $\mathrm{CD}$, when biological therapy is discontinued based only on clinical remission, disease relapse rates are $42 \%$ at 1 year, but these are reduced to $26 \%$ when therapy is stopped with mucosal healing. Similarly, for UC, 1 -year relapse rates vary from $50 \%$ in cases of clinical remission to $33 \%$ in those of mucosal healing. ${ }^{[18,31]}$ Fistulising peri-anal CD has consistently been associated with increased relapse rates after treatment withdrawal. A possible increased risk of relapse has been reported in complex $\mathrm{CD}$ with strictures and fistulas, but the data are inconclusive. ${ }^{[32,33]}$ Previous surgery alone has not been associated with an increased relapse rate. ${ }^{[34]}$

- Laboratory data. A high C-reactive protein (CRP) and faecal calprotectin (FC) at time of treatment withdrawal are associated with increased disease relapse. ${ }^{[35-37]}$ An optimal predictive cut-off for relapse for CRP was $6.1 \mathrm{mg} / \mathrm{L}$ and $305 \mu \mathrm{g} / \mathrm{g}$ for FC, although sensitivity and specificity for both were low $(\sim 70 \%)$. A low haemoglobin and raised white cell count $>6 \times 10^{9} / \mathrm{L}$ may increase risk of relapse. ${ }^{[34]}$ High infliximab trough levels at time of anti-TNF withdrawal are also associated with an increased relapse rate. ${ }^{[34]}$

Table 1. Induction and maintenance cost for the first year of biological therapy in South Africa

\begin{tabular}{llllll}
\hline Biological therapy & Induction & Cost, ZAR & Maintenance & Cost, ZAR & Total cost/year, ZAR \\
\hline Infliximab & $400 \mathrm{mg}^{*}$ weeks 0, 2 and 6 & 67520.52 & $400 \mathrm{mg}^{*}$ every 8 weeks & 112534.20 & 180054.72 \\
Adalimumab $^{\dagger}$ & $160 \mathrm{mg}$ week 0; 80 mg week 2 & 34571.60 & $40 \mathrm{mg}$ every other week & 113592.40 & 148164.00 \\
Golimumab $^{\ddagger}$ & 200 mg week 0; 100 mg week 2 & 31338.69 & $100 \mathrm{mg}$ every 4 weeks & 114908.53 & 146247.22
\end{tabular}


- IM therapy. Previous treatment failure with an IM prior to starting anti-TNF therapy was associated with increased disease recurrence after discontinuing the biological agent. ${ }^{[38]}$ Moreover, absence of IM therapy after stopping biological therapy was associated with a higher relapse rate in some studies. ${ }^{[18]}$

- Elevated levels of the cytokines. Elevated levels of the cytokines IL-17 and TNF alpha in the healed mucosa of patients with IBD may also predict early disease relapse after stopping biological therapy ${ }^{[39]}$ Colonoscopy and a colonic mucosal biopsy are not standard practice in otherwise well patients, and the introduction of cytokine analysis in this setting may be inappropriate. A clinical study examining serum inflammatory cytokines to predict disease relapse may yield useful results that could be easier to implement.

\section{Retreatment strategies after relapse}

Retreatment with the same biological agent used prior to discontinuation is safe and effective. A recent meta-analysis showed retreatment with the same anti-TNF agent induced clinical remission in an average of $80 \%$ of IBD patients, with similar outcomes in CD and UC. ${ }^{[18]}$ Much the same results were shown in the STORI trial. ${ }^{[19]}$ Longer follow-up data in retreatment studies confirmed remission rates in these patients ( $80-92 \%$ at 1 year). ${ }^{[20,36]}$

An important effect of retreatment is the high risk of immunisation resulting in hypersensitivity reactions and ultimately loss of drug response. This can be countered by concomitant IM therapy that reduces antibody formation, resulting in less infusion reactions and loss of response. ${ }^{[40]}$ Furthermore, discontinuation of IM during combination therapy resulted in secondary LOR and anti-TNF dose escalation in $24 \%$ of patients. ${ }^{[4]}$ A recent study showed infusion reactions in $24 \%$ of patients who were retreated with infliximab after a drug holiday. Seventeen percent had to discontinue infliximab altogether owing to the severity of the infusion reactions. However, patients on an IM during the drug holiday had fewer infusion reactions. ${ }^{[42]}$

\section{Discontinuing biological agents in special groups}

There are certain patient groups that respond differently to conventional drug treatment and withdrawal of treatment. These are discussed below:

- Pregnancy. Anti-TNF antibodies cross the placenta and because of increased risk of infection to the newborn have traditionally been discontinued in the third trimester. ${ }^{[43]}$ However, a recent Toronto consensus statement recommended that biological treatment should be continued during the entire pregnancy. ${ }^{[44]}$ Discontinuation of treatment increases the risk of disease flare in the third trimester or in the postpartum period. In a 2011 retrospective study by Seirafi et al., ${ }^{[45]} 14 \%$ relapsed in the third trimester and $32 \%$ in the first 3 weeks postpartum. A more recent study showed third-trimester relapse rates of $9.8 \%$ and 3 months postpartum relapse rates of $15.7 \%{ }^{[46]}$ Retreatment with the same biological agent in the same study during the postpartum period resulted in $100 \%$ clinical remission rates. The decision to stop or continue treatment during pregnancy should be individualised and patients with aggressive disease should probably be persuaded to remain on a biological agent throughout.

- Perianal CD. Data regarding treatment withdrawal in this group of patients are sparse. A 2005 study showed that only a third of patients with luminal perianal disease remained in clinical remission 1 year after stopping infliximab. ${ }^{[4]}$ In the ACCENT-II trial (a CD clinical trial evaluating infliximab in a new long-term treatment regimen in patients with fistulising $\mathrm{CD}$ ), only $36 \%$ of patients with fistulising perianal $\mathrm{CD}$ achieved a clinical response (inactive disease and closed fistulas) after 54 weeks of infliximab therapy. ${ }^{[48]}$ Withdrawal of infliximab in patients with fistulising perianal disease after clinical remission (healed mucosa, closed fistulas) resulted in a relapse rate of $24 \%$ in 1 year and $55 \%$ in 5 years, as shown in a recent study by Legué et al. ${ }^{[49]}$ Complex perianal $\mathrm{CD}$ also has a poor clinical response to long-term infliximab maintenance treatment, with a failure rate of $15.4 \%$ at 15 weeks and $>40 \%$ at 5 years. ${ }^{[50]}$ It appears that a combination of surgery and biological therapy remains the most effective treatment choice. ${ }^{[51]}$

- Postoperative prophylaxis. CD often recurs after surgical resection. Treatment with biological therapy was found to be the most effective way of reducing postoperative recurrence. Regueiro et al. ${ }^{[52]}$ noted a $100 \%$ disease recurrence in 1 year after stopping biological therapy after surgery. A disease recurrence rate of $83 \%$ was noted by Sorrentino et al. ${ }^{[53]} 4$ months after discontinuing infliximab after surgical resection. However, recent data suggest that longterm infliximab treatment after surgery prevents endoscopic - but not clinical - disease recurrence. ${ }^{[54]}$ Retreatment with the same biological drug in relapsed patients who discontinued biological therapy in this setting resulted in clinical remission in all.

- Pouchitis. This is often difficult to manage. Results with anti-TNF therapy for refractory pouchitis is reassuringly good. A recent systematic review showed that infliximab has $80 \%$ short-term and $50 \%$ long-term clinical efficacy in refractory pouchitis. ${ }^{[55]}$ However, there are no consistent long-term outcome data and it is unclear how long one should continue with therapy. ${ }^{[56]}$

\section{De-escalation strategies for biological therapy}

Strategies that can be employed when considering de-escalation of biological therapy in IBD are the following:

- Discontinuation of biological therapy altogether is a possible strategy. The evidence for this has been discussed above. This must be considered when the patient is in deep clinical remission and biological drug levels are low. It is strongly recommended for the patient to be administered the highest possible dose of an IM that he/she can tolerate, which may be a very low dose. In the event of a previous adverse event or intolerance to an IM, it is prudent to maintain the patient on the lowest possible dose to avoid infusion reactions when restarting biological therapy. Should it be necessary to restart therapy, all available evidence suggests that the last used drug will be effective in $>80 \%$ of patients. Therefore, one should restart with the biological agent last used.

- Another form of de-escalation is to reduce the dose of the biological agent or to increase the dosing frequency. In the landmark TAXIT (Trough concentration Adapted infliXImab Treatment) study, patients in clinical remission with infliximab trough levels $>7 \mu \mathrm{g} / \mathrm{mL}$ had dose de-escalation to a target trough level of $3-7 \mu \mathrm{g} / \mathrm{mL}$. De-escalation was done by reducing the dose to $5 \mathrm{mg} / \mathrm{kg}$ (if previously $10 \mathrm{mg} / \mathrm{kg}$ ) or by increasing the dose interval between infusions by 2 weeks (to a maximum of 12 weeks). Ninety-three percent of patients achieved the target range after dose reduction and remained in clinical remission. Fewer patients in the trough concentration dosing range discontinued treatment compared with those in the standard dosing group. ${ }^{[57]}$ However, in the TAILORIX study, which investigated tailored treatment with infliximab for active $\mathrm{CD}$, trough-level dosing in $\mathrm{CD}$ was not superior to symptom-based dosing in patients in remission. ${ }^{[58]}$ After achieving remission with adalimumab standard 2-weekly dosing in $\mathrm{CD}$, patients extended the dosing interval from 2 to 3 weeks, which resulted in sustained remission in $65 \%$ over 24 months, while in $35 \%$ the dosing frequency was reduced to 2 -weekly dosing. ${ }^{[59]}$ These findings have been duplicated in a similar study that was 
recently published. ${ }^{[60]}$ In another study, CD and UC patients with refractory disease who previously required high-dose infliximab $(10 \mathrm{mg} / \mathrm{kg})$ and subsequently achieved remission, were scheduled to reduce the dose by $1 \mathrm{mg} / \mathrm{kg}$ at each infusion to reach a target of $5 \mathrm{mg} / \mathrm{kg}$ infusion dose or a target trough level of $3-7 \mu \mathrm{g} / \mathrm{mL}$. The majority of patients $(n=18-20 ; 90 \%)^{[44]}$ in this cohort remained well and in clinical remission, with adequate drug levels. ${ }^{[61]}$ It seems, therefore, that a de-escalation strategy based on therapeutic drug monitoring can be effective, even in high-risk IBD patients with aggressive disease, who require dose escalation at some stage.

\section{Biological de-escalation: Who to target}

The authors believe that all IBD patients should be considered for de-escalation of biological therapy at some point in their disease course. The proviso should be that these patients should be in deep clinical remission and exhibit the following:

- healed intestinal mucosa

- normal inflammatory markers - white cell count, erythrocyte sedimentation rate and CRP

- $\mathrm{FC}<50 \mathrm{mg} / \mathrm{mL}$

- low serum drug level.

However, there are certain patient groups in whom biological treatment de-escalation should be instituted with caution. As they are prone to frequent disease exacerbations, biological therapy withdrawal should be carefully planned and only embarked upon in those with mucosal healing. Frequent follow-up and clinical assessments are imperative, with prompt re-introduction of biologics at the first sign of disease recurrence. The following are included:

- young males

- patients with perianal CD

- patients with persistent mucosal ulceration

- patients with persistent elevation of inflammatory markers

- high-risk patients requiring frequent biological dose escalation or re-introduction

- patients who have undergone multiple surgical operations.

More data on this subject matter will be available in due course, as ongoing studies are currently being conducted (BIOCYCLE project and SPARE study) to evaluate the safety and efficacy to cycle biological agents in patients in deep clinical remission. ${ }^{[62]}$ BIOCYCLE is a 6-year project that commenced in 2015. It aims to answer the question of biological drug withdrawal in patients with $\mathrm{CD}$ in an integrated, multidimensional and integrated fashion. SPARE is a prospective randomised controlled trial comparing infliximab-antimetabolites combination therapy to antimetabolites monotherapy and infliximab monotherapy in $\mathrm{CD}$ patients on combination therapy who are in sustained steroid-free remission.

\section{Conclusions}

It is safe to de-escalate biological therapy in patients in deep clinical remission and in those receiving combination therapy. Evidence is not so robust in patients being administered a biological agent as monotherapy; more studies are needed in this regard. Before de-escalation of therapy, a frank discussion on the risks and benefits of the decision is mandatory. Although not ideal, de-escalation of biological treatment is often necessitated by cost, safety concerns and patient choice. However, the choice to de-escalate therapy should always be weighed against the risk of disease recurrence. As a general rule, patients who are in clinical, biochemical and endoscopic remission are more likely to remain in remission for longer. Although the majority of patients will eventually relapse, one should give patients a drug holiday. Some will never need re-introduction of therapy again.

The treatment of IBD has advanced tremendously over the years. Currently, there is personalised treatment for IBD. The high-risk patient has been identified and should be persuaded to continue receiving biological treatment for a longer period. It is incumbent upon clinicians to ensure that patients receive adequate doses with appropriate dosing intervals to guarantee mucosal healing. Therapeutic drug monitoring is a valuable tool in the modern management of IBD and should be judiciously employed, especially in patients who fail to respond appropriately. Merely escalating the dose of biological therapy in response to a low trough level in a patient who is otherwise doing clinically well is inappropriate.

If concerned about stopping biological therapy outright, clinicians could consider either reducing the dose incrementally or increasing the dosing frequency. There is sufficient evidence for both strategies. It is reassuring to know that retreatment will be effective in most patients, and mostly with the same biological agent. Finally, also consider the psychological well-being of a patient with IBD off biological therapy, albeit only for a while.

Declaration. None.

Acknowledgements. None.

Author contributions. EF planned the article, sourced the references and wrote the initial draft. GW reviewed and edited the draft and added segments to various sections.

Funding. None.

Conflicts of interest. None.

1. Sparrow MP, Irving PM, Hanauer SB. Optimizing conventional therapies for inflammatory bowel disease. Curr Gastroenterol Rep 2009;11(6):496-503.

2. Engel MA, Neurath MF. New pathophysiological insights and modern treatment of IBD. J Gastroenterol 2010;45(6):571-583. https://doi.org/10.1007/s00535-010-0219-3

3. Hanauer SB, Cohen RD, Becker RV, 3rd, Larson LR, Vreeland MG. Advances in the management of Crohn's disease: Economic and clinical potential of infliximab. Clin Ther 1998;20(5):1009-1028.

4. Trinder MW, Lawrance IC. Efficacy of adalimumab for the management of inflammatory bowel disease in the clinical setting. J Gastroenterol Hepatol 2009;24(7):1252-1257. https://doi.org/10.1111/ j.1440-1746.2009.05786.x

5. Sandborn WJ, Feagan BG, Marano C, et al. Subcutaneous golimumab maintains clinical response in patients with moderate-to-severe ulcerative colitis. Gastroenterology 2014;146(1):96-109. https://doi. org/10.1053/j.gastro.2013.05.048

6. McLean LP, Shea-Donohue T, Cross RK. Vedolizumab for the treatment of ulcerative colitis and Crohn's disease. Immunotherapy 2012;4(9):883-898. https://doi.org/10.2217/imt.12.85

7. Sandborn WJ, Feagan BG, Fedorak RN, et al. A randomized trial of ustekinumab, a human interleukin-12/23 monoclonal antibody, in patients with moderate-to-severe Crohn's disease. Gastroenterology 2008;135(4):1130-1141. https://doi.org/10.1053/.j.gastro.2008.07.014

8. Cote-Diagneault J, Bouin M, Lahaie R, Colombel J-F, Poitras P. Biologics in inflammatory bowel diseaese: What are the data? United Eur Gastroenterol J 2015;3(5):419-428. https://doi.
bowel bowel diseaese: What are the
org/10.1177/2050640615590302

9. Mao EJ, Hazlewood GS, Kaplan GG, Peyrin-Biroulet L, Anathakrishnan AN. Systematic review and meta-analysis: Comparative efficacy of immunosuppressants and biologics for reducing hospitalization and surgery in Crohn's disease and ulcerative colitis. Aliment Pharmacol Ther 2017;45(1):3-13. https:// doi.org/10.1111.apt13847

10. Bultman E, Kuipers EJ, van der Woude CJ. Systematic review: Steroid withdrawal in anti-TNF treated patients with inflammatory bowel disease. Aliment Pharmacol Ther 2010;32(3):313-323. https://doi. org/10.1111/j1365-2036.2010.04373.x

11. Roda G, Jharap B, Neeaj N, Colombel J-F. Loss of response to anti-TNFs: Definition, epidemiology and management. Clin Transl Gastroenterol 2016; 7(1):e135. https://doi.org/10.1038/ctg.2015.63

12. Reinglas J, Gonczi L, Kurt Z, Bessissow T, Lakatos PL. Positioning of old and new biologicals and small molecules in the treatment of inflammatory bowel diseases. World J Gastroenterol 2018;24(32):3567-3582. https://doi.org/10.3748/wjg.v24.i32.3567

13. Hindryckx P, vande Casteele N, Novak G, et al. The expanding therapeutic armamentarium for inflammatory bowel disease: How to choose the right drug[s] for our patients? J Crohn's Colitis inflammatory bowel disease: How to choose the right drug

14. Hommes DW. Risks and benefits of biologic therapy for IBD. J Pediatr Gastroenterol Nutr 2009;48(Suppl 2):S52-S53. https://doi.org/10.1097/MPG.0b013e3181a11785
4. Hommes DW. Risks and benefits of biologic therapy for IBD. I Ped

15. Bahler C, Vavricka SR, Schoepfer AM, Brungger B, Reich O. Trends in prevalence, mortality, health care utilization and health care costs of Swiss IBD patients: A claims data based study of the years 2010, 2012 and 2014. BMC Gastroenterol 2017;17(1):138. https://doi.org/10.1186/s12876-017-0681-y

16. Engel T, Ungar B, Ben-Haim G, Levhar N, Eliakim R, Ben-Horin S. Re-phrasing the question: A simple tool for evaluation of adherence to therapy in patients with inflammatory bowel disease. United Eur Gastroenterol J 2017;5(6):880-886. https://doi.org/10.1177/2050640616687838

17. Bucci C, Zingone F, Tammaro S, Iovino P, Santonicola A, Ciacci C. Factors predicting the adherence to the therapy of Italian IBD patients. Gastroenterol Res Pract 2017;2017:6719345. https://doi. org/10.1155/2017/6719345

18. Gisbert JP, Marin AC, Chaparro M. The risk of relapse after anti-TNF discontinuation in inflammatory bowel disease: Systematic review and meta-analysis. Am J Gastroenterol 2016;111(5):632-647. https:// doi.org/10.1038/ajg.2016.54 
19. Louis E, Mary J-Y, Vernier-Massouille G, et al. Maintenance of remission among patients with Crohn's disease on antimetabolite therapy after infliximab therapy is stopped. Gastroenterology 2012;142(1);6317. disease on antimetabolite therapy after inflix
https://doi.org/10.1052/.j.gastro.2011.09.043

20. Steenholdt C, Molazahi A, Ainsworth MA, et al. Outcome after discontinuation of infliximab in patients Steenholdt C, Molazahi A, Ainsworth MA, et al. Outcome after discontinuation of infliximab in patients
with inflammatory bowel disease in clinical remission: An observational Danish single center study. Scand J Gastroenterol 2012;47(5):518-527. https://doi.org/10.3109/00365521.2012.660541

21. Kennedy NA, Warner B, Johnston EL, et al. Relapse after withdrawal from anti-TNF therapy for inflammatory bowel disease: An observational study, plus systematic review and meta-analysis. Aliment Pharmacol Ther 2016;43(8):910-923. https://doi.org/10.3109/00365521.2012.660541

22. Molander P, Farkkila M, Salminen K, et al. Outcome after discontinuation of TNF-alpha-blocking therapy in patients with inflammatory bowel disease in deep remission. Inflamm Bowel Dis 2014;20(6):1021-1028. https://doi.org/10.1097/mib.0000000000000052

23. Torres J, Boyapati RK, Kennedy NA, Louis E, Colombel JF, Satsangi J. Systematic review of effects of withdrawal of immunomodulators or biologic agents from patients with inflammatory bowel disease. Gastroenterology 2015;149(7):1716-1730. https://doi.org/10.1053/j.gastro.2015.08.055

24. Clarke $\mathrm{K}$, Regueiro $\mathrm{M}$. Stopping immunomodulators and biologics in inflammatory bowel disease patients in remission. Inflamm Bowel Dis 2012;18(1):174-179. https://doi.org/10.1002/ibd.21792

25. Papamichael K, vande Casteele N, Gils A, et al. Long-term outcome of patients with Crohn's disease who discontinued infliximab therapy upon clinical remission. Clin Gastroenterol Hepatol 2015;13(6):1103-1110. https://doi.org/10.1016/j.cgh.2014.11.026

26. Pariente B, Laharie D. Why, when and how to de-escalate therapy in inflammatory bowel diseases. Aliment Pharmacol Ther 2014;40(4):338-353. https://doi.org/10.1111/apt.12838

27. Blonski W, Buchner AM, Lichtenstein GR. Clinical predictors of aggressive/disabling disease: Ulcerative colitis and Crohn disease. Gastroenterol Clin North Am 2012;41(2):443-462. https://doi.org/10.1016/j. gtc. 2012.01 .008

28. Brant SR, Picco MF, Achkar JP, et al. Defining complex contributions of NOD2/CARD15 gene mutations, age at onset, and tobacco use on Crohn's disease phenotypes. Inflamm Bowel Dis 2003;9(5):281-289.

29. Shah SC, Khalili H, Gower-Rousseau C, et al. Sex-based differences in incidence of inflammatory bowel diseases - pooled analysis of population-based studies from Western countries. Gastroenterology 2018;155(4):1079-1089. https://doi.org/10.1053/.gastro.2018.06.043

30. Coughlan A, Wylde R, Lafferty L, et al. A rising incidence and poorer male outcomes characterise early onset paediatric inflammatory bowel disease. Aliment Pharmacol Ther 2017;45(12):1534-1541. https:// doi.org/10.1111/apt.14070

31. Farkas K, Lakatos PL, Szucs M, et al. Frequency and prognostic role of mucosal healing in patients with Crohn's disease and ulcerative colitis after one-year of biological therapy. World J Gastroenterol 2014;20(11):2995-3001. https://doi.org/10.3748/wjg.v20.111.2995

32. Papamichael $\mathrm{K}$, Cheifetz AS. Defining and predicting deep remission in patients with perianal fistulizing Crohn's disease on anti-tumor necrosis factor therapy. World J Gastroenterol 2017;23(34):6197-6200. https://doi.org/10.3748/wg.v23.i34.6197

33. Savoye-Collet C, Savoye G, Koning E, Dacher JN, Lerebours E. Fistulizing perianal Crohn's disease: Contrast-enhanced magnetic resonance imaging assessment at 1 year on maintenance anti-TNF-alpha therapy. Inflamm Bowel Dis 2011;17(8):1751-1758. https://doi.org/10.1002/ibd.21568

34. Zhou J, Li Y, Gong J, Zhu W. Frequency and risk factors of surgical recurrence of Crohn's disease after primary bowel resection. Turk J Gastroenterol 2018;29(6):655-663. https://doi.org/10.5152/ tig.2018.17774

35. Mooiweer E, Severs M, Schipper ME, et al. Low fecal calprotectin predicts sustained clinical remission in inflammatory bowel disease patients: A plea for deep remission. J Crohn's Colitis 2015;9(1):50-55. https:// doi.org/10.1093/ecco-jcc/jju003

36. Farkas K, Lakatos PL, Nagy F, et al. Predictors of relapse in patients with ulcerative colitis in remission after one-year of infliximab therapy. Scand J Gastroenterol 2013;48(12):1394-1398. https://doi.org/10.31 09/00365521.2013.845906

37. Henriksen M, Jahnsen J, Lygren I, et al. C-reactive protein: A predictive factor and marker of inflammation in inflammatory bowel disease. Results from a prospective population-based study. Gut 2008;57(11):1518-1523. https://doi.org/10.1136/gut.2007.146357

38. Vermeire S, van Assche G, Rutgeerts P. Laboratory markers in IBD: Useful, magic, or unnecessary toys? Gut 2006;55(3):426-431. https://doi.org/10.1136/gut.2005.069476:

39. Rismo R, Olsen T, Cui G, et al. Normalization of mucosal cytokine gene expression levels predicts longterm remission after discontinuation of anti-TNF therapy in Crohn's disease. Scand J Gastroenterol 2013;48(3):311-319. https://doi.org/10.3109/00365521.2012.758773

40. Chauvin A, le Thuaut A, Belhassan M, et al. Infliximab as a bridge to remission maintained by antimetabolite therapy in Crohns's disease: A retrospective study. Dig Liver Dis 2014;46(8):695-700. https://doi.org/10.1016/j.dld.2014.04.012

41. Viazis N, Koukouratos T, Anastasiou J, et al. Azathioprine discontinuation earlier than 6 months in Crohn's disease patients started on anti-TNF therapy is associated with loss of response and the need for anti-TNF dose escalation. Eur J Gastroenterol Hepatol 2015;27(4):436-441. https://doi.org/10.1097/ meg.0000000000000303
42. Lichtenstein L, Ron Y, Kivity S, et al. Infliximab-related infusion reactions: Systematic review. J Crohn's Colitis 2015;9(9):806-815. https://doi.org/10.1093/ecco-jcc/jjv096

43. Gisbert JP, Chaparro M. Safety of anti-TNF agents during pregnancy and breastfeeding in women

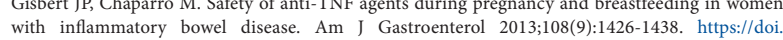
org/10.1038/ajg.2013.171

44. Nguyen GC, Seow CH, Maxwell C, et al. The Toronto consensus statements for the management of inflammatory bowel disease in pregnancy. Gastroenterology 2016;150(3):734-757. https://doi org/10.1053/j.gastro.2015.12.003

45. Seirafi M, de Vroey B, Amiot A, et al. Factors associated with pregnancy outcome in anti-TN treated women with inflammatory bowel disease. Aliment Pharmacol Ther 2014;40(4):363-373. https://doi.org/10.1111/apt.12833

46. Zelinkova Z, van der Ent C, Bruin KF, et al. Effects of discontinuing anti-tumor necrosis factor therapy during pregnancy on the course of inflammatory bowel disease and neonatal exposure. Clin Gastroenterol Hepatol 2013;11(3):318-321. https://doi.org/10.1016/j.cgh.2012.10.024

47. Domenech E, Hinojosa J, Nos P, et al. Clinical evolution of luminal and perianal Crohn's disease after inducing remission with infliximab: How long should patients be treated? Aliment Pharmacol The 2005;22(11-12):1107-1113. https://doi.org/10.1111/j.1365-2036.2005.02670.x

48. Sands BE, Anderson FH, Bernstein CN, et al. Infliximab maintenance therapy for fistulising Crohn's disease. N Engl J Med 2004;350(9):876-885. https://doi.org/10.1056/NEJMMoa30815
dister

49. Legué C, Brochard C, Bessi G, et al. Outcomes of perianal fistulising Crohn's disease following anti-TNFa treatment discontinuation. Inflamm Bowel Dis 2018;24(6):1107-1113. https://doi. org/10.1093/ibd/izy008

50. Uchino M, Ikeuchi H, Bando T, et al. Long-term efficacy of infliximab maintenance therapy fo perianal Crohn's disease. World J Gastroenterol 2011;7(9):1174-1179. https://doi.org/10.3748/wjg v17.i9.1174

51. Park EJ, Song K-H, Baik SH, et al. The efficacy of infliximab combined with surgical treatment for fistulizing perianal Crohn's disease: Comparative analysis according to fistula types. Asian J Surg 2018;41(5):438-447. https://doi.org/10.1016/j.asjsur.2017.06.05

52. Regueiro M, Schraut W, Baidoo L, et al. Infliximab prevents Crohn's disease recurrence after ileal resection. Gastroenterology 2009;136(2):441-450. https://doi.org/10.1053/j.gastro.2008.10.051

53. Sorrentino D, Marino M, Dassopoulos T, Zarifi D, Del Bianco T. Low dose infliximab for prevention of postoperative recurrence of Crohn's disease: Long term follow-up and impact of infliximab trough levels and antibodies to infliximab. PLOS ONE 2015;10(12):e0144900. https://doi.org/10.1371/ journal.pone. 0144900

54. Regueiro M, Feagan BG, Zou B, et al. Infliximab reduces endoscopic, but not clinical, recurrence of Crohn's disease after ileocolonic resection. Gastroenterology 2016;150(7):1568-1578. https://doi. org/10.1053/j.gastro.2016.02.072

55. Herfarth HH, Long MD, Isaacs KL. Use of biologics in pouchitis: A systematic review. J Clin Gastroenterol 2015;49(8):647-654. https://doi.org/10.1097/MCG.000000000000036

56. Viazis N, Giakoumis M, Koukouratos T, et al. Long term benefit of one year infliximab administratio for the treatment of chronic refractory pouchitis. J Crohn's Colitis 2013;7(10):e457-e460. https://doi org/10.1016/j.crohns.2013.02.018

57. Pouillon L, Ferrante M, van Assche G, et al. Mucosal healing and long-term outcomes of patient with inflammatory bowel diseases receiving clinic-based vs trough concentration-based dosing of infliximab. Clin Gastroenterol Hepatol 2018;16(8):1276-1283. https://doi.org/10.1016/. cgh.2017.11.046

58. D'Haens GR, Vermeire S, Lambrecht G, et al. 692 drug-level based dosing versus symptombased dose adaptation in patients with Crohn's disease: A prospective, randomized multicenter study (TAILORIX). Gastroenterology 2016;150(4 Suppl 1):S143. https://doi.org/10.1016/S00165085(16)30583-2

59. Van Steenbergen S, Bian S, Vermeire S, van Assche G, Gils A, Ferrante M. Dose de-escalation to adalimumab $40 \mathrm{mg}$ every 3 weeks in patients with Crohn's disease - a nested case-control study. Aliment Pharmacol Ther 2017;45(7):923-932. https://doi.org/10.1111/apt.13964

60. Pouillon L, Lamoureux A, Pineton de Chambrun G, et al. Dose de-escalation to adalimumab 40 mg every three weeks in patients with inflammatory bowel disease - a multicenter, retrospective observational study. Dig Liver Dis 2019;51(2):236-241. https://doi.org/10.1016/j.dld.2018.10.022

61. Paul S, Roblin X, Peyrin-Biroulet L. Infliximab de-escalation based on trough levels in patients with inflammatory bowel disease. Aliment Pharmacol Ther 2015;42(7):939-940. https://doi.org/10.1111 apt. 13335

62. Satsangi J, Kitten O, Chavez M, et al. How to apply for and secure EU funding for collaborative IBD research projects. J Crohn's Colitis 2016;10(3):363-370. https://doi.org/10.1093/ecco-jcc/jiv237

Accepted 29 July 2019 